\title{
Elective open abdominal aortic aneurysm repair: a seven-year experience
}

\author{
Stuart MacKenzie \\ Judith R Swan \\ Cate D'Este \\ Allan D Spigelman \\ Discipline of Surgical Science, \\ Faculty of Health, The University of \\ Newcastle and Clinical Governance \\ Unit, Hunter Area Health Service, \\ NSW, Australia
}

Introduction: The seven-year experience of elective abdominal aortic aneurysm (AAA) repair of a vascular surgical unit in a teaching hospital was reviewed to determine the factors associated with in-hospital mortality.

Methods: All patients who underwent elective open repair of an AAA between July 1, 1991, and June 30, 1998, were identified using International Classification of Diseases Ninth Revision (ICD-9) codes. Twenty-four variables were selected for investigation by reviewing the published literature and by discussion with local vascular surgeons. Data were obtained by retrospective medical record review. Variables were first analysed by univariate analysis, and those with a p-value up to 0.25 were included in multivariate analysis.

Results: Of the 219 patients reviewed, 8 (3.7\%, 95\% confidence interval, 1.6\%, 7.1\%) died during the admission. The mean age of patients was 69.9 years, and $81 \%$ of them were male. Univariate analysis found that female sex, renal artery involvement in the aneurysm, and aortic cross-clamp duration of 90 min or greater were significantly associated with mortality. Multivariate analysis found that female sex, use of a bifurcated graft, and performance of an additional procedure at the time of operation were the only variables independently associated with mortality.

Discussion: Use of a bifurcated graft was a significant prognostic variable on logistic regression analysis confirming that the technical difficulty of the operation and the morphology of the aneurysm are important factors in determining mortality. Why women may be at higher risk for death is unclear. This study also highlights that caution is required when interpreting raw audit data.

Keywords: elective abdominal aortic aneurysm repair, mortality, audit, morphology, risk factors

\section{Introduction}

Most reports indicate that survival after elective abdominal aortic aneurysm (AAA) surgery approximates 95\% (Semmens et al 1987; Bradbury et al 1988; Scott and Wilson 1993; Katz et al 1994; Dardik et al 1999). This compares with a survival rate of only $20 \%$ from a ruptured AAA (Semmens et al 1987; Chosky et al 1999). To further improve survival after elective surgery, a better understanding of the factors associated with risk is necessary.

We present the seven-year experience of elective AAA repair of a vascular surgical unit in a teaching hospital. The aim of the study was to investigate factors associated with mortality. The results of retrospective analysis of prognostic factors are considered to determine those associated with high mortality so as to further inform decision making. 


\section{Methods}

All patients who underwent operation for repair of an AAA between July 1, 1991, and June 30, 1998, were identified using International Classification of Diseases Ninth Revision (ICD-9) codes. All records were reviewed, and those having open elective repair of an AAA were selected. Patients having aortic replacement surgery for other reasons or an aortic graft revision were not included in the study. All relevant information was obtained from the patients' medical records. The information was recorded by a single investigator (SM).

Variables were chosen for investigation by reviewing the published literature on risk factors for AAA surgery and by discussion with local vascular surgeons. This process identified 24 variables that were investigated for association with in-hospital mortality following elective AAA repair. The variables were mainly preoperative factors, with several operative factors also assessed. All variables were divided into categories (Table 1). Thirty-day mortality would have been another useful outcome measure, but this information was not available.

The proportion of fatal cases was calculated with exact binomial 95\% confidence intervals (CI). Characteristics associated with fatality were assessed by univariate analysis using Fisher's exact test. Variables with a p-value of 0.25 or less on univariate analyses were then included in logistic regression analysis to determine factors associated with mortality after adjusting for other variables in the model (multivariate analysis). The statistical significance of variables was assessed using the Wald test, and standard errors were adjusted for the effects of clustering within surgeons.

\section{Results}

Two hundred and forty-nine patients were identified as having had an elective AAA repair during the study period. Of these, 22 sets of notes could not be located, 6 patients had nothing in their notes to suggest that they had undergone an AAA repair, and documentation for the relevant admission was missing in 2 cases. This left 219 patients who were included in the study.

One hundred and seventy-seven patients (81\%) were male. The mean age was 69.9 years, and age did not differ between males and females $\left(\mathrm{t}_{217}=-1.16, \mathrm{p}=0.25\right)$. Some data were unavailable in a number of the files. However, the size of the aneurysm (18\%), admission creatinine level
(11\%), and aortic cross-clamp duration (26\%) were the only variables for which data were missing for more than $5 \%$ of patients.

Forty-nine patients (22\%) had a history of chronic obstructive airways disease. Sixty patients were current smokers at the time of their operation, 124 had previously smoked, and 33 had never smoked. Therefore, $85 \%$ of patients were either current or previous smokers.

Admission systolic blood pressure was documented for 214 patients. It was greater than $140 \mathrm{mmHg}$ in 149 patients (70\%), and greater than $180 \mathrm{mmHg}$ in 14 patients $(7 \%)$.

Angina was recorded as affecting 32 of 218 patients (15\%). Seventy-one of the 219 patients (32\%) had previously suffered a myocardial infarction. A history of previous cardiac revascularization was present in 51 of 219 patients (23\%). Forty-six patients from 217 (21\%) had a recent investigation demonstrating cardiac ischemia. Nineteen out of 216 patients ( $9 \%$ ) had a pre-existing cardiac arrhythmia, while 11 from 218 patients (5\%) had a documented history of cardiac failure.

There was documentation of previous cerebrovascular disease in 29 cases (13\%) and of peripheral vascular disease in 64 cases (29\%). One patient had a creatinine level greater than $0.36 \mathrm{mmol} / \mathrm{L}$ on admission, and $11 \mathrm{had}$ creatinine levels between 0.18 and $0.36 \mathrm{mmol} / \mathrm{L}$. Twenty-five patients $(11 \%)$ did not have a creatinine level recorded on admission. Eleven patients were diabetic and 2 of these were on insulin treatment with the remaining 9 managed with diet or oral medications.

A straight aortic graft was used in 160 patients (75\%). A bifurcated graft was used in 53 patients. The type of graft was not recorded in 6 patients. Aortic cross-clamping was recorded as lasting more than $90 \mathrm{~min}$ in 24 patients $(15 \%)$. Fifty-six patients (26\%) did not have the aortic cross-clamp time documented. Two hundred and fourteen patients had the aortic cross-clamp position documented. In 29 of these patients the clamp was positioned suprarenally, and in 185 patients the clamp was positioned was infrarenally. The aneurysm involved the renal arteries in 4 patients.

Thirty-eight patients had an additional procedure performed at the time of their operation. Of the patients who died, 3 had an additional procedure performed. One patient had bilateral renal endarterectomies, the second had a thrombectomy of the right external iliac artery, and the third had a repair of an incisional hernia.

Eight of the patients or $3.7 \%$ (95\% CI, 1.6\%, 7.1\%) died following AAA repair during the indexed admission. Three patients died from multisystem organ failure and another 
Table I Association of variables with death from any cause for elective AAA repair - results of univariate analysis

\begin{tabular}{|c|c|c|c|}
\hline Variable & Category & $\begin{array}{r}\text { Nr of deaths } \\
(\%)\end{array}$ & $\begin{array}{r}\text { p-value (Fisher's } \\
\text { exact test) }\end{array}$ \\
\hline \multirow[t]{2}{*}{ Gender } & Male & $3(1.7)$ & 0.007 \\
\hline & Female & $5(11.9)$ & \\
\hline \multirow[t]{2}{*}{ COAD } & Yes & $2(4.1)$ & 1.000 \\
\hline & No & $6(3.5)$ & \\
\hline \multirow[t]{2}{*}{ Current angina } & Yes & $2(6.3)$ & 0.333 \\
\hline & No & $6(3.2)$ & \\
\hline \multirow[t]{2}{*}{ History of myocardial infarction } & Yes & $3(4.2)$ & 0.716 \\
\hline & No & $5(3.3)$ & \\
\hline \multirow[t]{2}{*}{ Cardiac revascularization } & Yes & $\mathrm{I}(2.0)$ & 0.685 \\
\hline & No & $7(4.2)$ & \\
\hline \multirow[t]{2}{*}{ Objective investigation demonstrating cardiac ischemia } & Yes & $2(4.3)$ & 0.678 \\
\hline & No & $6(3.5)$ & \\
\hline \multirow[t]{2}{*}{ Pre-existing arrhythmia } & Yes & $\mathrm{I}(5.3)$ & 0.527 \\
\hline & No & $7(3.6)$ & \\
\hline \multirow[t]{2}{*}{ History of cardiac failure } & Yes & $1(9.1)$ & 0.344 \\
\hline & No & $7(3.4)$ & \\
\hline \multirow[t]{2}{*}{ History of cerebrovascular disease } & Yes & I (3.4) & 1.000 \\
\hline & No & $7(3.7)$ & \\
\hline \multirow[t]{2}{*}{ History of peripheral vascular disease } & Yes & $\mathrm{I}(\mathrm{I} .6)$ & 0.442 \\
\hline & No & $7(4.5)$ & \\
\hline \multirow[t]{2}{*}{ Graft type } & Straight & $4(2.5)$ & 0.108 \\
\hline & Bifurcated & $4(7.5)$ & \\
\hline \multirow[t]{2}{*}{ Cross-clamp position } & Infrarenal & $5(2.7)$ & 0.079 \\
\hline & Suprarenal & $3(10.3)$ & \\
\hline \multirow[t]{2}{*}{ Renal artery involvement in the aneurysm } & Yes & $2(50)$ & 0.007 \\
\hline & No & $6(2.9)$ & \\
\hline \multirow[t]{2}{*}{ Additional procedure performed at the time of the operation } & Yes & $3(7.9)$ & 0.156 \\
\hline & No & $5(2.9)$ & \\
\hline \multirow[t]{2}{*}{ Creatinine level on admission } & $<0.18 \mathrm{mmol} / \mathrm{L}$ & $6(3.3)$ & 0.080 \\
\hline & $>0.18 \mathrm{mmol} / \mathrm{L}$ & $2(16.7)$ & \\
\hline \multirow[t]{2}{*}{ Age } & $<70$ years & I (I.0) & 0.068 \\
\hline & $70+$ years & $7(6.1)$ & \\
\hline \multirow[t]{2}{*}{ Weight } & $<80 \mathrm{~kg}$ & $7(5.3)$ & 0.158 \\
\hline & $80+\mathrm{kg}$ & $\mathrm{I}(\mathrm{I} .2)$ & \\
\hline \multirow[t]{2}{*}{ Smoking history } & Smoker & $5(2.7)$ & 0.105 \\
\hline & Non smoker & $3(9.1)$ & \\
\hline \multirow[t]{2}{*}{ Systolic blood pressure on admission } & $<180 \mathrm{mmHg}$ & $7(3.5)$ & 0.423 \\
\hline & $>180 \mathrm{mmHg}$ & I (7.I) & \\
\hline \multirow[t]{2}{*}{ Systolic blood pressure on admission } & $<140 \mathrm{mmHg}$ & $2(3.1)$ & 1.000 \\
\hline & $140+\mathrm{mmHg}$ & $6(4.0)$ & \\
\hline \multirow[t]{2}{*}{ Cross-clamp duration } & $<60$ min & I (I.4) & 0.403 \\
\hline & $60+\min$ & $5(5.3)$ & \\
\hline Cross-clamp duration & $<90$ min & $3(2.2)$ & 0.042 \\
\hline & $90+\min$ & $3(12.5)$ & \\
\hline Diabetes status & Yes & $0(0)$ & 1.000 \\
\hline & No & $8(3.8)$ & \\
\hline Surgeon & Surgeon I & $2(2.5)$ & $0.128^{a}$ \\
\hline & Surgeon 2 & $5(8.1)$ & \\
\hline & Surgeon 3 & I (7.I) & \\
\hline & Surgeon 4 & $0(0)$ & \\
\hline & Surgeon 5 & $0(0)$ & \\
\hline
\end{tabular}

${ }^{a}$ Chi square test, not Fisher's exact test.

Abbreviation: COAD, chronic obstructive airways disease. 
3 patients died from complications relating to excess bleeding. The remaining 2 deaths were from cardiac causes.

On univariate analysis (Table 1), 3 variables were found to be significantly associated with mortality at the 0.05 significance level:

- female sex $(\mathrm{p}=0.007)$;

- renal artery involvement in the aneurysm $(\mathrm{p}=0.007)$;

- aortic cross-clamp duration of $90 \mathrm{~min}$ or greater $(\mathrm{p}=0.042)$.

Eight other variables had a p-value of $<0.25$ and were therefore included in multivariate analysis. These were female sex, bifurcated graft, suprarenal cross-clamping, performance of an additional procedure at the time of the operation, admission creatinine, age, weight, and a history of smoking. Aortic cross-clamp duration was excluded as there were too many missing values. Renal artery involvement in the aneurysm was also removed from the regression because there were only 4 patients in this group, causing the $\mathrm{CI}$ of the odds ratio (OR) to vary by more than 1500 and making meaningful interpretation impossible. The operating surgeon could not be included in the regression analysis as two of the surgeons recorded no deaths, giving null values in the model.

Logistic regression analysis found that 3 variables were independently associated with mortality following elective AAA repair (Table 2). These were female sex, OR 24.2 (95\% CI, 3.7-160.6, $\mathrm{p}=0.001)$; use of a bifurcated graft, OR 9.9 (95\% CI, 1.6-60.7, p=0.013); and performance of an additional procedure at the time of the operation, OR 5.4 (95\% CI, 1.0-29.0, $\mathrm{p}=0.047$ ).

\section{Discussion}

The number of procedures performed in Australia for resection and replacement of the abdominal aorta is increasing, with numbers rising from 2294 in 1995-1996 to 2587 in 1996-1997 (MSAC 1999). This is not surprising given that the population is aging, with the proportion of those aged over 65 expected to increase from $12 \%$ in the year 2000 to $16 \%$ by 2025 (Christophidis 1988). There is

Table 2 Logistic regression analysis results: multivariate analysis

\begin{tabular}{lrrrrr}
\hline & $\begin{array}{r}\text { Estimate } \\
\text { of OR }\end{array}$ & \multicolumn{2}{c}{$\begin{array}{c}95 \% \mathbf{C l} \\
\text { for OR }\end{array}$} & \multicolumn{2}{c}{ Wald test } \\
\cline { 5 - 6 } & 24.24 & $3.66-160.59$ & 3.305 & p-value \\
\hline Female sex & 9.89 & $1.61-60.73$ & 2.474 & 0.001 \\
Bifurcated graft & 5.44 & $1.02-28.98$ & 1.983 & 0.047 \\
Additional procedure & &
\end{tabular}

Abbreviations: $\mathrm{OR}$, odds ratio; $\mathrm{Cl}$, confidence interval. also evidence that the incidence and prevalence of AAA is increasing (Pleumeekers 1994). As the caseload increases, so too does the need to gain a better understanding of the reasons for poor outcomes.

The mortality rate here of $3.7 \%$ is comparable to other reports. However, of the patients operated on electively for AAA at the John Hunter Hospital, Newcastle, Australia, during the study period, 22 patients were not included because their notes could not be located. Of these 22 patients, 5 were reported to have died. Adding these 5 patients to the study, results in a mortality rate of $5.4 \%$, which is still comparable with published rates. While subtracting these patients from the analysis reduces the power of the results reported, data were available for more than $95 \%$ of patients included in the study (for all but 3 variables).

Patients with renal artery involvement in their aneurysm were included in this study because they were not identified until operation, and were therefore treated as being part of the same group preoperatively. The finding that only 4 patients had renal artery involvement makes it difficult to interpret the increase in mortality that this was associated with and forced the removal of this variable from the multivariate analysis. An increase in mortality with renal artery involvement is expected as it requires suprarenal clamping and is associated with a more difficult procedure, which is likely to take longer.

The use of a bifurcated graft was found to be independently significant despite not being significant at univariate analysis. This confirms that the technical difficulty of the operation and the morphology of the aneurysm are important factors in determining mortality. Most of the additional procedures performed (also an independently significant variable) were for intraoperative complications. The significance of this variable further suggests that the technical difficulty of the operation is important. Perhaps the use of more sophisticated 3-dimensional imaging is justified to better identify the morphology of aneurysms and determine if features can be identified that suggest increased risk at operation.

The finding that female sex is an independent risk factor for death supports two previous reports that have found women to have higher mortality with univariate analysis (Katz et al 1994; Dardik et al 1999). The explanation for why women may be at higher risk is unclear. On the other hand, Evans et al (2000) failed to detect poorer outcomes for females in their prospective study of outcome after surgery for ruptured abdominal aortic aneurysm. 
We acknowledge the limitations of retrospective analyses such as this. Moreover, the rare nature of the outcomes results in low power of such studies. However, this study does suggest that there is scope for improvement with regard to the significant omissions from the medical record detected, such as cross-clamping duration, size of the aneurysm, and the admission creatinine level. These have clinical and medicolegal ramifications, which should stimulate prospective evaluations of documentation. This falls within the remit of the clinical governance aspect of surgical practice as described by Scally and Donaldson (1998, p 61).

Clinical governance is a system through which NHS organisations are accountable for continuously improving the quality of their services and safeguarding high standards of care by creating an environment in which excellence in clinical care will flourish.

If excellence is to be achieved, then there needs to be accurate data concerning outcomes. (For more detailed information, see http://www.hunter.health.nsw.gov.au/ clinicalgovernance.)

This study demonstrates the importance of considered statistical analysis of audit data. Crude audit data can be a misleading tool for comparing outcomes of care in surgical practice. The results also show that simple statistical analysis can lead to inaccurate conclusions. If clinical data are to be used as a tool to compare outcomes of care, it is suggested that advanced analytical methods are considered, particularly when the outcome variables involve small numbers, such as mortality following elective surgery. We emphasize the need for caution in the interpretation of raw audit data by colleagues, consumers, and healthcare management.

The introduction of endovascular aneurysm repair might diminish the relevance of these findings; however, the newer procedure is still finding its place and may only be appropriate in $30 \%$ of patients (Myers 2000; Woodburn et al 2001), if that (Collin and Murie 2001).

\section{Acknowledgments}

This work formed part of a successful Bachelor of Medical Science project, Faculty of Medicine and Health Sciences, the University of Newcastle. We thank the Vascular Surgery Unit, John Hunter Hospital, for their constructive comments.

\section{References}

Bradbury AW, Adam DJ, Makhdoomi KR, et al. 1988. A 21-year experience of abdominal aortic aneurysm operations in Edinburgh. Br J Surg, $85: 645-7$.

Dardik A, Lin JW, Gordon TA, et al. 1999. Results of elective abdominal aortic aneurysm repair in the 1990s: a population-based analysis of 2335 cases. J Vasc Surg, 30:985-95.

Chosky SA, Quick CR, Wilmink ABM. 1999. Ruptured abdominal aortic aneurysm in the Huntingdon district: a 10-year experience. Ann $R$ Coll Surg Engl, 81:27-31.

Christophidis N. 1988. The family physician and the ageing of Australia. Aust Fam Physician, 7:513.

Collin J, Murie JA. 2001. Endovascular treatment of abdominal aortic aneurysm: a failed experiment. Br J Surg, 88:1281-2.

Evans SM, Adam DJ, Bradbury AW. 2000. The influence of gender on outcome after ruptured abdominal aortic aneurysm. J Vasc Surg, $32: 258-62$.

Katz DJ, Stanley JC, Zelenock GB. 1994. Operative mortality rates for intact and ruptured abdominal aortic aneurysms in Michigan: an eleven year statewide experience. J Vasc Surg, 19:808-17.

[MSAC] Medicare Services Advisory Committee. May 1999. Endoluminal grafting for abdominal aortic aneurysm. MSAC application 1006. Final assessment report. Canberra: MSAC.

Myers KA. 2000. Endoluminal grafting for abdominal aortic aneurysms: where will the buck stop? Aust N Z J Surg, 70:767-8.

Pleumeekers HJCM, Hoes AW, van der Does E, et al. 1994. Epidemiology of abdominal aortic aneurysms. Eur J Vasc Surg, 8:119-28.

Scally G, Donaldson LJ. 1998. Clinical governance and the drive for quality improvement in the new NHS in England. BMJ, 317:61-5.

Scott RAP, Wilson NM, Ashton HA, et al. 1993. Is surgery necessary for abdominal aortic aneurysms less than $6 \mathrm{~cm}$ in diameter? Lancet, 342:1395-6.

Semmens JB, Lawrence-Brown MMD, Norman PE, et al. 1987. The Quality of Surgical Care Project: benchmark standards of open resection for abdominal aortic aneurysm in Western Australia. Aust NZ J Surg, 68:404-10.

Semmens JB, Norman PE, Lawrence-Brown MM, et al. 2000. Influence of gender on outcome from ruptured abdominal aortic aneurysm. $\mathrm{Br} \mathrm{J}$ Surg, 87:191-4

Woodburn KR, Chant H, Davies JN, et al. 2001. Suitability for endovascular aneurysm repair in an unselected population. Br J Surg, 88:77-81. 
